\title{
Suprascapular nerve block in the treatment of hemiplegic shoulder pain Mohja A. El-Badawy
}

\author{
Department of Physical Medicine, \\ Rheumatology and Rehabilitation, Faculty of \\ Medicine, Ain Shams University, Cairo, Egypt \\ Correspondence to Mohja A. El-Badawy, PhD, \\ Department of Physical Medicine, \\ Rheumatology and Rehabilitation, Lecturer \\ in Physical Medicine, Ain Shams University \\ Hospitals, Cairo, Egypt \\ Tel: +201111434418, +20100504 8716, \\ Fax: 26830729 \\ e-mail: mohjaelbadawy@gmail.com
}

Received 1 September 2013

Accepted 1 November 2013

Egyptian Rheumatology \& Rehabilitation 2014, 41:20-27

\begin{abstract}
Objective
The aim of the study was to study the effectiveness of suprascapular nerve block (SSNB) in reducing pain and increasing range of motion (ROM) in hemiplegic shoulder pain and to compare them with therapeutic ultrasound (U/S).

Design

The study was designed as a randomized controlled trial.

\section{Setting}

The study was conducted in the Department of Physical Medicine, Rheumatology and Rehabilitation.

\section{Patients and methods}

Stroke patients with hemiplegic shoulder pain who met the inclusion criteria were included in the present study and allocated to the SSNB or U/S groups. Both groups were given the same standard program of ROM exercise, and visual analog scale score of pain, passive maximum ROM, and Croft Disability Questionnaire at second and fourth weeks were evaluated.

\section{Results}

Twenty stroke patients were equally allocated to the SSNB and U/S groups. There was a significant improvement in visual analog scale scores and Croft Disability Questionnaire at the second and fourth weeks in the SSNB group. For ROM outcome of the SSNB group, the increase in flexion at the second and fourth weeks was $18.96 \pm 11.73$ and $34.93 \pm 17.58$ and in abduction was $22.26 \pm 15.48$ and $41.12 \pm 22.02$, respectively. SSNB produced faster relief of pain and more effective restoration of ROM compared with $\mathrm{U} / \mathrm{S}$.
\end{abstract}

\section{Conclusion}

The present study suggested that SSNB is a safe and effective treatment for hemiplegic shoulder pain. It was more effective than therapeutic $\mathrm{U} / \mathrm{S}$ in reducing pain score and improving ROM and upper limb function.

\section{Keywords:}

hemiplegic, shoulder pain, suprascapular nerve block, ultrasound

Egypt Rheumatol Rehabil 41:20-27

(c) 2014 Egyptian Society for Rheumatology and Rehabilitation

1110-161X

\section{Introduction}

Shoulder pain is a distressing complication of hemiplegia and is reported as one of the most common complications of stroke [1].

Hemiplegic shoulder pain is associated with reduction in functional use of the upper limb, interference with rehabilitation, and increased length of hospitalization [2].

The prevalence of shoulder pain has been reported to be as high as $70 \%$ in the first 12 months following stroke [3].

Investigation into the cause of hemiplegic shoulder pain has reported a multifactorial etiology. The most common noncentral, musculoskeletal etiologies of hemiplegic shoulder pain include adhesive capsulitis, bicipital tendonitis, subacromial bursitis, subluxation, and rotator cuff pathologies, with up to one-third of patients having multiple contributing factors [4].
Biomechanical changes result from a combination of paralysis, fluctuation in muscle tone, and prolonged shoulder immobility, which lead to postural malalignment [5].

It should be noted that not all shoulder pain is associated with complications of limb flaccidity and may be attributable to spasticity or central pain concepts [1].

The period of hospitalization may be prolonged in hemiplegic patients with shoulder pain [2]. It is an annoying complication that may be refractory to treatment and cause poor recovery [1]. Therefore, the goals of treatment are pain reduction and improvement of range of motion (ROM). As pain decreases, an exercise program can be initiated to improve ROM [5].

The conclusion of cause that produces hemiplegic shoulder pain and the effective treatment methods are still controversial and inconclusive [2]. 
Physiotherapy is the main treatment program that is always prescribed in these patients, including physical modalities such as ultrasound (U/S), transcutaneous electrical stimulation, and therapeutic exercises. Many rehabilitation physicians give additional intra-articular corticosteroid injection. However, evidences of the effectiveness of the intra-articular steroid injections are difficult to interpret [6].

The effect of $\mathrm{U} / \mathrm{S}$ in management of soft tissue disorders of the shoulder was found to be of little clinical benefit [7]. In a study by Suethanapornkul et al. [6], U/S seems to be of some value in the management of hemiplegic shoulder pain but is not effective in some cases.

These inconclusive results led us to study a new effective intervention.

Suprascapular nerve block (SSNB) is an effective and safe method for pain relief and increases ROM in many groups of patients who have shoulder pain such as nonspecific shoulder pain [8], chronic shoulder pain [9], rotator cuff tendonitis [10], rheumatoid arthritis [11], frozen shoulder [6], and pain after arthroscopic shoulder surgery [12].

The signs and symptoms of hemiplegic shoulder pain are similar to those found in a nonhemiplegic painful stiff shoulder (adhesive capsulitis) [6]. Therefore, the objectives of the present study were to study the effects of SSNB in reducing pain and increasing ROM in hemiplegic shoulder pain and to compare these effects with therapeutic U/S, which is a conventional treatment program for hemiplegic shoulder pain.

\section{Patients and methods}

Wehad already taken written consent from all participants in this study after complete and clear explanation of the aim, steps, and hazards of the procedure. In addition, we took verbal consent from all patients subjected to clinical examination during participants' selection. Twenty hemiplegic patients who were admitted at the Ain Shams University Hospital and who had shoulder pain with limited ROM on paretic limb were recruited to the present study. All patients were diagnosed as stroke, were conscious, well cooperated, and willing to enroll in the study. Patients' demographics included age, sex, details of etiology, time period since stroke, affected side, Brunnstrom stage of upper extremity, and presence of spasticity. All measurements were double checked before and after the procedure.

Three physical diagnosis maneuvers were tested in all patients: the Neer impingement test, the speed test, and the acromioclavicular shear test [13]. In the Neer impingement test, the patient's arm was elevated through forward flexion by the examiner passively bringing greater tuberosity against the anteroinferior border of the acromion. An abnormal finding is the provocation of pain; such provocation is said to be indicative of impingement of the rotator cuff or injury to the supraspinatus muscle [14].

In the speed test, the examiner actively resisted the shoulder elevated in forward flexion at the plane of the scapula in a completely extended elbow with the forearm medially rotated by the patient. Pain in the bicipital groove is said to be indicative of bicipital tendon involvement [15].

The acromioclavicular shear test is said to indicate pathology at the acromioclavicular joint. This maneuver is performed with the patient sitting; the examiner cups his/her hands anteriorly on the clavicle and posteriorly on the spine of the scapula. Squeezing the heel of the hands together elicits pain in the presence of acromioclavicular inflammation [16].

Exclusion criteria included the following:

(1) Cognitive deficit that precluded patients from reliably using subjective outcome measures scales [Thai Mental State Examination (TMSE < 24)] [17].

(2) Language deficits (inability to follow two-stage command).

(3) Allergy to proposed injection agents (10 $\mathrm{ml}$ of $2 \%$ lidocaine).

(4) Any contraindication to U/S.

(5) Visual analog scale (VAS) score less than 50.

(6) Degenerative changes at the glenohumeral joint as shown by a standard anteroposterior radiograph.

All included patients were allocated into either the $\operatorname{SSNB}(n=10)$ group or the U/S $(n=10)$ group.

\section{Suprascapular nerve anatomy}

Suprascapular nerve is a mixed nerve, both motor and sensory, originated in the upper trunk of the brachial plexus - C5 and C6 roots - receiving in over 50\% contributions from the fourth cervical root. It crosses the deep posterior triangle of neck, below omohyoid muscle and trapezium, entering the suprascapular incisure below the superior transverse scapular ligament [18] (Fig. 1).

Suprascapular artery and vein run above this ligament. The nerve provides two motor branches to supraspinatus muscle and sensory branches to acromioclavicular and glenohumeral articulation. It continues its descending course by passing the spinoglenoid incisure, under the 
inferior transverse scapular ligament present in 50\% of people. It passes toward the infraspinatus fossa, in which it provides three to four motor branches to infraspinatus muscle [19].

The sensory components innervate the upper and posterior parts of capsule of the shoulder in addition to the acromioclavicular articulation, coracoclavicular ligament, and subacromial bursa. They provide 70\% of shoulder articulation sensitivity, as the rest takes place through axillary nerve branches [20]. These sensory branches emerge from the suprascapular nerve before and after passing below the superior transverse scapular ligament. Two to three of them pass through the scapular incisure and reach the base of the coracoid process, where they perforate supraspinatus muscle, extending toward the subacromial bursa. For obtaining the interruption of sensory impulses of the involved structures, it is important to know these anatomic details so that SSNB develops in a healthy way [21].

\section{Technique of suprascapular nerve block}

Ten milliliters of $2 \%$ lidocaine without adrenaline was injected using the indirect block of suprascapular nerve by the Dangoisse technique [22] (Fig. 2). A 25-G needle was introduced through the skin $2 \mathrm{~cm}$ cephaloid to the midpoint of the spine of the scapula, with the patient sitting and the upper limbs bending beside the body. Anatomic landmarks must be palpated, such as clavicle, acromioclavicular articulation, acromion, scapular spine, and coracoid process. This entire area was sterilized with alcohol, and the needle was advanced parallel to the blade of the scapula until bony contact was made in the floor of the suprascapular fossa. The needle must be aspired before infusion of anesthetic solution so that there is no risk this solution enters the blood stream directly. This

\section{Figure 1}

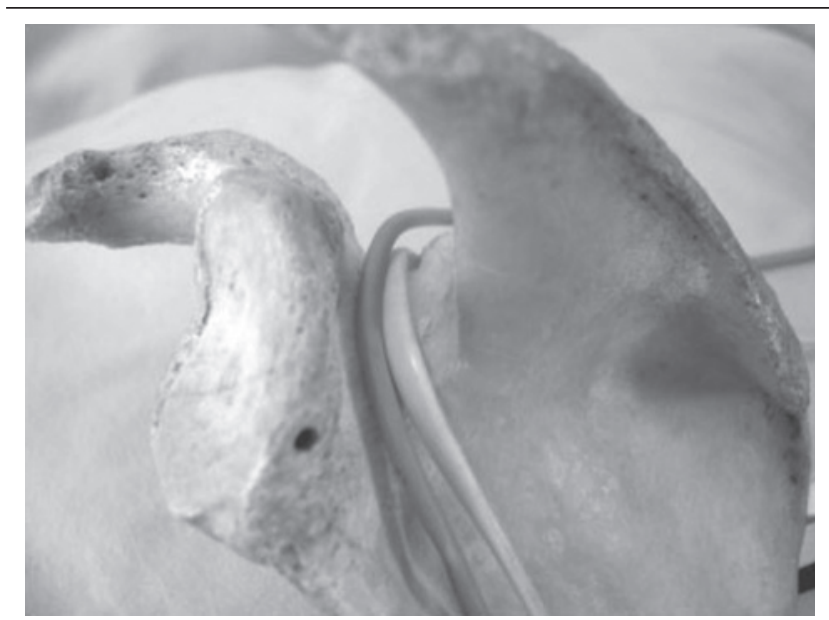

Posterior view of the scapula bone model. Suprascapular nerve (light gray) from incisure to spinoglenoid fossa. technique has previously been demonstrated to be safe, and it effectively blocks the articular branches of the suprascapular nerve. Paresthesia was not observed, and the risk for pneumothorax and brachial plexus injury was eliminated.

\section{Ultrasound or the control group}

Application of $1.0-2 \mathrm{~W} / \mathrm{cm}^{2}$ around the shoulder joint for 10 min was carried out (three times/week) for 4 weeks.

Patients in both groups received standard programs of ROM and stretching exercises on the paretic upper limb, occupational therapy, and ambulatory training.

The primary outcome measurements were obtained at baseline and at second and fourth weeks of the present study. They included (a) VAS - pain score that was documented by asking the patient to place a mark on a horizontal $10-\mathrm{cm}$ pain VAS. The left end of the pain VAS was marked ' 0 ', whereas the right end was marked '100'. On this scale, higher numbers indicate more perceived pain. A baseline pain VAS value of 50 or more was required for study entry [23]. (b) Passive maximum ROM of flexion and abduction of the painful shoulder were measured with goniometry.

The secondary outcomes of disability and quality of life were measured using the Croft Disability Questionnaire (CDQ) (Table 1). The CDQ includes 22 questions regarding disability associated specifically with shoulder pain. Scoring gives 1 point for each 'Yes'. Minimal level of detectable change ( $90 \%$ confidence interval) will be 3 points [24].

\section{Figure 2}

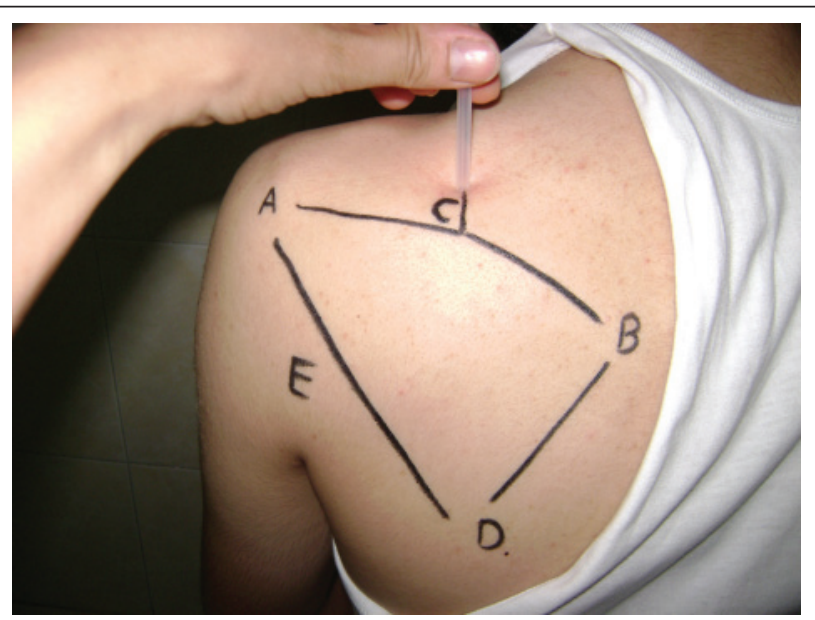

Posterior view of the suprascapular nerve block using the Dangoisse technique. Landmarks are indicated as follows: acromion and lateral end of the scapular spine (a), medial end of the scapular spine (b), midpoint of the scapular spine (c), inferior angle of the scapula (d), and lateral border of the scapula (e). The needle is aligned $2 \mathrm{~cm}$ superior to the midpoint of the scapular spine parallel to the blade of the scapula. 


\begin{tabular}{|c|c|c|}
\hline & Yes & No \\
\hline \multicolumn{3}{|l|}{$\begin{array}{l}\text { Because of pain in my shoulder, I move my arm } \\
\text { or hand with some difficulty }\end{array}$} \\
\hline \multicolumn{3}{|l|}{$\begin{array}{l}\text { I have difficulty in taking bath because of my } \\
\text { shoulder }\end{array}$} \\
\hline \multicolumn{3}{|l|}{$\begin{array}{l}\text { Because of my shoulder trouble, I get dressed } \\
\text { with help from someone else }\end{array}$} \\
\hline \multicolumn{3}{|l|}{$\begin{array}{l}\text { I get dressed more slowly than usual because of } \\
\text { my shoulder }\end{array}$} \\
\hline \multicolumn{3}{|l|}{$\begin{array}{l}\text { I have trouble putting on a shirt, blouse, or jacket } \\
\text { because of my shoulder problem }\end{array}$} \\
\hline \multicolumn{3}{|l|}{$\begin{array}{l}\text { Because of my shoulder problem, I fasten my } \\
\text { clothing with some difficulty (e.g. buttons, zips, } \\
\text { or bra) }\end{array}$} \\
\hline \multicolumn{3}{|l|}{$\begin{array}{l}\text { Because of my shoulder problem, I change } \\
\text { position frequently in bed at night }\end{array}$} \\
\hline \multicolumn{3}{|l|}{$\begin{array}{l}\text { I cannot lie on my right side at night because of } \\
\text { my shoulder }\end{array}$} \\
\hline \multicolumn{3}{|l|}{$\begin{array}{l}\text { I cannot lie on my left side at night because of } \\
\text { my shoulder }\end{array}$} \\
\hline \multicolumn{3}{|l|}{$\begin{array}{l}\text { I stay at home most of the time because of my } \\
\text { shoulder problem }\end{array}$} \\
\hline \multicolumn{3}{|l|}{$\begin{array}{l}\text { Because of my shoulder problem, I do less of the } \\
\text { daily household jobs than I would usually do }\end{array}$} \\
\hline \multicolumn{3}{|l|}{$\begin{array}{l}\text { I avoid heavy jobs around the house because of } \\
\text { my shoulder trouble }\end{array}$} \\
\hline \multicolumn{3}{|l|}{$\begin{array}{l}\text { Because of my shoulder, I do not carry any } \\
\text { shopping }\end{array}$} \\
\hline \multicolumn{3}{|l|}{$\begin{array}{l}\text { Because of my shoulder trouble, I am cutting } \\
\text { down on some of my usual sports or more active } \\
\text { pastimes }\end{array}$} \\
\hline \multicolumn{3}{|l|}{$\begin{array}{l}\text { Because of my shoulder trouble, I am not doing } \\
\text { any of my usual physical recreation or more } \\
\text { active pastimes }\end{array}$} \\
\hline \multicolumn{3}{|l|}{$\begin{array}{l}\text { Because of my shoulder, I try to get other people } \\
\text { to do things for me }\end{array}$} \\
\hline \multicolumn{3}{|l|}{$\begin{array}{l}\text { My shoulders make me more irritable and bad } \\
\text { tempered with people than usual }\end{array}$} \\
\hline \multicolumn{3}{|l|}{$\begin{array}{l}\text { Because of my shoulder, I have more minor } \\
\text { accidents (e.g. dropping things) }\end{array}$} \\
\hline \multicolumn{3}{|l|}{ I sleep less well because of my shoulder } \\
\hline \multicolumn{3}{|l|}{$\begin{array}{l}\text { Because of my shoulder, I rest more often during } \\
\text { the day }\end{array}$} \\
\hline \multicolumn{3}{|l|}{$\begin{array}{l}\text { My appetite is not very good because of my } \\
\text { shoulder problem }\end{array}$} \\
\hline $\begin{array}{l}\text { Because of my shoulder, I have trouble writing or } \\
\text { typing }\end{array}$ & & \\
\hline
\end{tabular}

Statistical analysis was performed by SPSS program version 21 for Windows (IBM, New York, USA.). Baseline characteristics were compared between groups by using the Mann-Whitney $U$-test or the $\chi^{2}$-test depending on the type of data, with significance at $P$-value less than 0.05. Pain VAS score, ROM, and CDQ score were compared between groups at second and fourth weeks using the independent $t$-test, with significance at $P$-value less than 0.05. Decrease in VAS and CDQ scores and increase in ROM of flexion and abduction of both groups at second and fourth weeks were compared using the Mann-Whitney $U$-test.

\section{Results}

Twenty stroke patients who attended the Physical Medicine, Rheumatology and Rehabilitation Outpatient Clinic, Ain Shams University Hospitals between September 2012 and June 2013 and who met the inclusion criteria were recruited to the present study. They were equally allocated randomly into two study groups: the SSNB group and the U/S group.

The groups did not differ significantly at baseline for personal characteristics or main outcome measurements except for baseline range of shoulder flexion and abduction (Table 2).

Pain VAS scores were reduced in both SSNB and U/S groups at second and fourth weeks after intervention, with a statistically significant difference of VAS scores between the groups at second and fourth weeks (Table 3).

Reduced pain VAS score in the SSNB group was more than in the U/S group during both follow-up periods, with a statistically significant difference at both second and fourth weeks (Table 4).

In both SSNB and U/S groups, there was an increase in mean ROM in both flexion and abduction positions at second and fourth weeks. However, a statistically significant difference was evidenced between the groups for the range of abduction at fourth week only (Table 3).

There was a significant difference in increasing ROM between the SSNB and U/S group in both flexion and abduction positions (Table 4).

The CDQ scores were reduced in both SSNB and U/S groups at second and fourth weeks after intervention, with a statistically significant difference between groups at second and fourth weeks (Table 3).

However, a significant difference was shown in the decreasing CDQ scores between the SSNB and U/S groups at second week only (Table 4).

There were no complications during the study period, and the injection was well tolerated by most of the patients (Figs 3-6).

\section{Discussion}

Our result showed SSNB with 2\% lidocaine by indirect technique described by Dangoisse et al. [22]; it was effective, safe, and with good compliance for reducing pain and improving ROM and upper limb function in hemiplegic shoulder pain syndrome. 
Compared with therapeutic U/S, SSNB was significantly better for reducing pain, increasing ROM, and decreasing shoulder disability score at second and fourth weeks post-treatment.

In the present study, the presence of actual motor stages (Brunnstrom stages) did not affect the preference of treatment procedure.

The infusion of local anesthetic into the suprascapular fossa (SSNB) interferes with the sodium channel function, preventing the spread of action potentials in the axons of suprascapular nerve [25].
Gado and Emery [26] suggested that the prolonged analgesic effect of SSNB might be because of an effect on $\mathrm{C}$ fibers that interrupts the cycle of feedback amplification that can occur in chronic pain.

Wassef [27] studied SSNB in frozen shoulder with reflex sympathetic dystrophy and concluded that sympathetic blockade at the level of suprascapular nerve for the management of frozen shoulder of reflex sympathetic dystrophy proved to be a highly specific procedure, in terms of sympathetically mediated shoulder pain.

\section{Table 2 Demographic data and main outcome measures}

\begin{tabular}{|c|c|c|c|}
\hline Characteristics & SSNB group $(n=10)$ & $\mathrm{U} / \mathrm{S}$ group $(n=10)$ & $P$-value \\
\hline Age (years) (mean $\pm \mathrm{SD})$ & $50 \pm 3.30$ & $51.7 \pm 3.89$ & 0.306 \\
\hline Sex $\delta: ㅇ ㅜ$ & $3: 2$ & $3: 2$ & 1.000 \\
\hline $\begin{array}{l}\text { Type of stroke ( } n \text { ) (infarction: } \\
\text { hemorrhage) }\end{array}$ & $7: 3$ & $6: 4$ & 0.548 \\
\hline Affected side ( $n)$ (right : left) & $4: 6$ & $5: 5$ & 0.653 \\
\hline Stroke duration (weeks) & $7.50 \pm 1.84$ & $7.40 \pm 1.65$ & 0.900 \\
\hline $\begin{array}{l}\text { Pain duration at onset (weeks) } \\
\text { (mean } \pm \text { SD) }\end{array}$ & $5.4 \pm 2.12$ & $5.4 \pm 1.65$ & 1.000 \\
\hline TMSE score (points) $(24: 25: 26)$ & $4: 5: 1$ & $6: 4: 0$ & 0.471 \\
\hline Baseline VAS score & $81 \pm 9.94$ & $78 \pm 10.33$ & 0.517 \\
\hline Spasticity (present : absent) & $5: 5$ & $4: 6$ & 0.653 \\
\hline Brunnstrom stage (I : II : III) & $3: 4: 3$ & $2: 6: 2$ & 0.670 \\
\hline \multicolumn{4}{|l|}{ Baseline ROM (mean \pm SD) } \\
\hline Flexion & $37.12 \pm 8.63$ & $51.18 \pm 10.54$ & 0.004 \\
\hline Abduction & $29.9 \pm 7.02$ & $39.71 \pm 11.20$ & 0.030 \\
\hline Baseline CDQ score & $17.80 \pm 1.62$ & $17.8 \pm 1.03$ & 1.000 \\
\hline \multicolumn{4}{|c|}{ Positive physical examination maneuvers } \\
\hline Neer test (positive : negative) ${ }^{a}$ & $1: 4$ & $3: 7$ & 0.606 \\
\hline Speed test (positive : negative) ${ }^{a}$ & $3: 2$ & $1: 1$ & 0.653 \\
\hline $\begin{array}{l}\text { Acromioclavicular shear test } \\
\text { (positive : negative) }^{\mathrm{a}}\end{array}$ & $3: 7$ & $3: 7$ & 1.000 \\
\hline
\end{tabular}

CDQ, croft disability questionnaire; ROM, range of motion; SSNB, suprascapular nerve block; TMSE, thai mental state examination; U/S, ultrasound; VAS, visual analog scale.

\section{Figure 3}

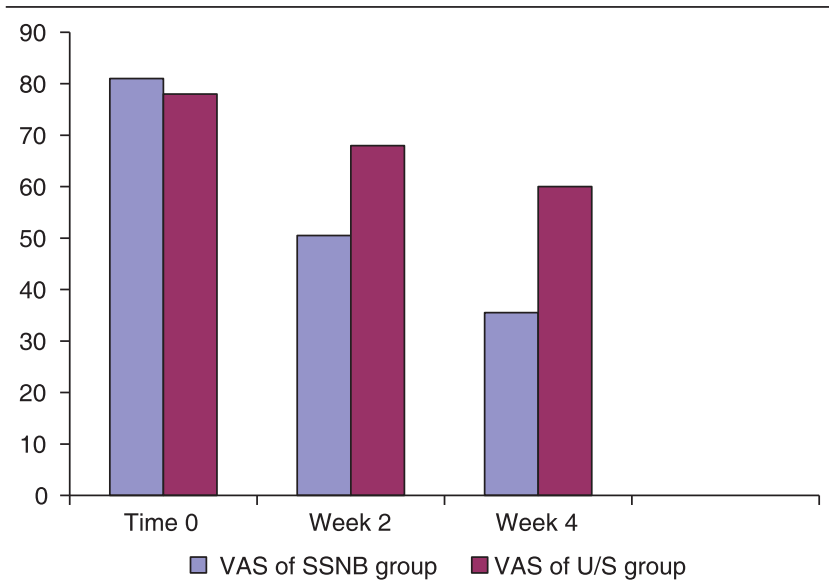

Visual analog scale (VAS) pain scores in the suprascapular nerve block (SSNB) and ultrasound (U/S) groups at baseline and at weeks 2 and 4.

\section{Figure 4}

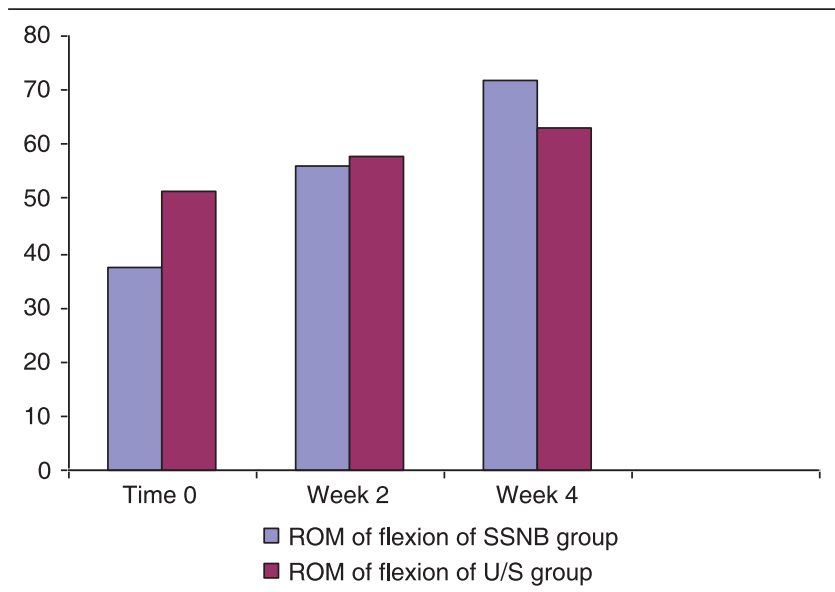

Range of motion (ROM) of flexion in the suprascapular nerve block (SSNB) and ultrasound (U/S) groups at baseline and at weeks 2 and 4. 
Figure 5

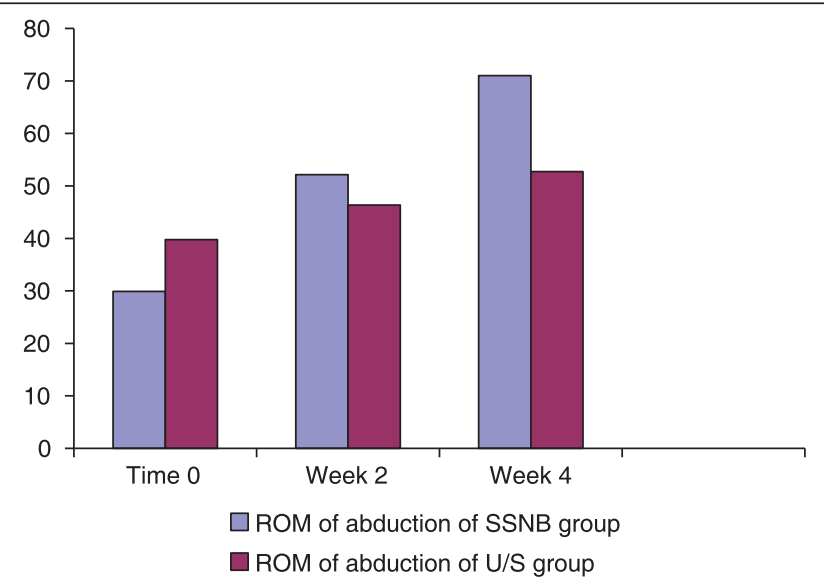

Range of motion (ROM) of abduction in the suprascapular nerve block (SSNB) and ultrasound (U/S) groups at baseline and at weeks 2 and 4

\section{Figure 6}

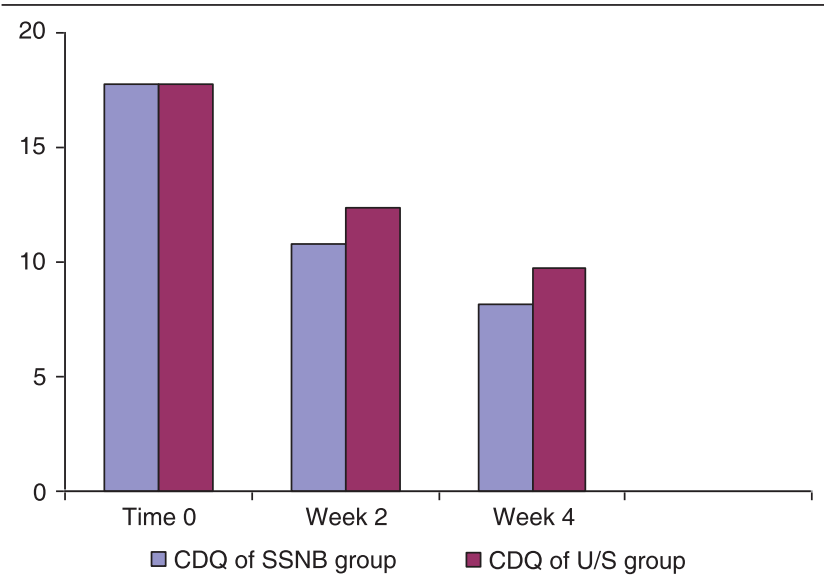

Croft Disability Questionnaire (CDQ) scores in the suprascapular nerve block (SSNB) and ultrasound (U/S) groups at baseline and at weeks 2 and 4 .

Table 3 Mean score of pain VAS and ROM and CDQ at baseline, second, and fourth weeks in the study groups

\begin{tabular}{lccc}
\hline Variables & SSNB group $(n=10)$ Mean \pm SD & U/S group $(n=10)$ Mean \pm SD & $P$-value between groups ${ }^{*}$ \\
\hline VAS at baseline & $81 \pm 9.94$ & $78 \pm 10.33$ & 0.517 \\
VAS at second week & $50.5 \pm 9.56$ & $68 \pm 11.11$ & 0.001 \\
VAS at fourth week & $35.5 \pm 11.41$ & $60 \pm 10.54$ & 0.000 \\
ROM of flexion at baseline & $37.12 \pm 8.63$ & $51.18 \pm 10.54$ & 0.004 \\
ROM of flexion at second week & $56.08 \pm 12.65$ & $58.09 \pm 10.79$ & 0.707 \\
ROM of flexion at fourth week & $72.05 \pm 15.82$ & $63.32 \pm 11.30$ & 0.173 \\
ROM of abduction at baseline & $29.9 \pm 7.03$ & $39.77 \pm 11.20$ & 0.030 \\
ROM of abduction at second week & $52.16 \pm 15.76$ & $46.36 \pm 10.75$ & 0.349 \\
ROM of abduction at fourth week & $71.02 \pm 21.28$ & $52.71 \pm 10.82$ & 0.026 \\
CDQ at baseline & $17.8 \pm 1.61$ & $17.8 \pm 1.03$ & 1.000 \\
CDQ at second week & $10.8 \pm 1.23$ & $12.4 \pm 1.17$ & 0.008 \\
CDQ at fourth week & $8.20 \pm 1.62$ & $9.8 \pm 1.61$ & 0.040
\end{tabular}

$\mathrm{CDQ}$, croft disability questionnaire; ROM, range of motion; SSNB, suprascapular nerve block; U/S, ultrasound; VAS, visual analog scale;

${ }^{*}$ Comparison between groups at baseline, second, and fourth weeks, significant at $P$-value $<0.05$.

Table 4 Mean score of decreasing pain VAS score, increasing ROM, and decreasing CDQ score at second and fourth weeks in both groups

\begin{tabular}{lccc}
\hline Variables & $\begin{array}{c}\text { SSNB group }(n=10) \\
\text { Mean } \pm \text { SD }\end{array}$ & $\begin{array}{c}\text { U/S group }(n=10) \\
\text { Mean } \pm \text { SD }\end{array}$ & $\begin{array}{c}P \text {-value between } \\
\text { groups }^{*}\end{array}$ \\
\hline Decreasing VAS at second week & $29.50 \pm 10.12$ & $10 \pm 2.36$ & 0.000 \\
Decreasing VAS at fourth week & $43.50 \pm 12.70$ & $17.5 \pm 3.54$ & 0.001 \\
Increasing ROM of flexion at second week & $18.96 \pm 11.73$ & $6.92 \pm 3.56$ & 0.006 \\
Increasing ROM of flexion at fourth week & $34.93 \pm 17.58$ & $12.11 \pm 5.11$ & 0.001 \\
Increasing ROM of abduction at second week & $22.26 \pm 15.48$ & $6.59 \pm 2.29$ & 0.005 \\
Increasing ROM of abduction at fourth week & $41.12 \pm 22.02$ & $13.08 \pm 2.58$ & 0.001 \\
Decreasing CDQ at second week & $7.00 \pm 1.41$ & $5.40 \pm 1.35$ & 0.019 \\
Decreasing CDQ at fourth week & $9.60 \pm 1.95$ & $8.00 \pm 1.76$ & 0.071 \\
\hline
\end{tabular}

$\mathrm{CDQ}$, croft disability questionnaire; ROM, range of motion; SSNB, suprascapular nerve block; U/S, ultrasound; VAS, visual analog scale. *Significant at $P$-value $<0.05$.

The most significant motor restoration strategies require active or passive movement to improve upper-extremity motor function. The applicability of treatment currently under study, such as constraintinduced movement therapy [28], robotics [29], and functional electric stimulation [30], will be limited, if the hemiplegic shoulder pain syndrome cannot be better managed. Pain on movement will discourage upper-extremity use and may cause patients to use their arm in productive activity less than their motor capacity or may allow future assistive technologies. 
The result of the present study also implicates that the long head of biceps and the rotator cuff (particularly the supraspinatus insertion) are common pain generators in hemiplegic shoulder pain syndrome. The most accepted role for the biceps tendon is to center the humeral head in the glenoid fossa and to reduce vertical translation. The instability of the shoulder in case of hemiplegia may explain the presence of bicipital tendonitis [31].

Like the long head of biceps, the supraspinatus is a vertical stabilizer of the glenohumeral joint. These two vertical stabilizers of the glenohumeral joint are so frequently involved, supporting Cailliet's contention that downward stretching of the joint capsule and surrounding musculotendinous structures causes injury and thus pain [32].

However, Lo et al. [33] reported that 50\% of the stroke patients had adhesive capsulitis and $44 \%$ had shoulder subluxation in arthrographic examinations of the patients with hemiplegic shoulder pain.

The results of the present study are in accordance with the study by Boonsong et al. [3] who showed that SSNB produced a faster relief of pain than U/S in hemiplegic patients, but they did not find any significant difference for restoration of ROM.

In a prospective, randomized, comparison crossover investigation, SSNB decreased the severity and frequency of perceived pain and increased compliance with the rehabilitation program in patients with rotator cuff tendinitis [10].

Our results are in accordance with the study by Allen et al. [1] who studied the effect of SSNB compared with placebo on 66 stroke patients. The results of the study showed that SSNB could relieve pain symptoms in individuals with mechanical shoulder pain after stroke and could provide improvement in the upper limb function.

Yasar et al. [34] found in their study similar efficacies of intra-articular steroid injection and SSNB in hemiplegic patients, but some controversial issues about the side effects related to steroid injection lead us to think that SSNB may be a more convenient method in stroke patients with hemiplegic shoulder pain, for whom a specific etiologic diagnosis has not been made.

In a retrospective study that investigated the efficacy of SSNB in treating rotator cuff tendonitis, $88 \%$ of the patients had significant pain relief, and many authors claimed that SSNB may be a safer alternative than injections involving steroid exposure [35]. It was reported that rotator cuff tear might be seen in about one-third of patients with hemiplegia $[28,33]$. Hence, it is necessary to avoid repeated steroid injections, particularly because of their atrophic effects.

Some reported side effects of SSNB were transient vagal symptoms and local tenderness at the injection site [36]. However, we did not determine any adverse events related to injection in the present study.

Although our data suggested that SSNB reduces hemiplegic shoulder pain in patients with stroke, there are some limitations in our study, such as small patient group, lack of placebo group, and short-term followup. No use of U/S or MRI in diagnosis of hemiplegic shoulder pain and no use of any guide for interventions such as U/S may be seen as a limitation.

Our aim was to find a convenient injection method that can be used easily and safely in outpatient clinic to break the vicious cycle of hemiplegic shoulder pain. The gradual reduction in the pain levels indicated that this vicious cycle was broken.

SSNB is a simple, safe, and inexpensive technique to relieve pain originating from the hemiplegic shoulder [37].

In clinical practice, therapeutic U/S has to be performed in a physical therapy unit; hence, there is a poor compliance in some patients. However, SSNB has an advantage that the patient could receive a home program for ROM exercise after nerve block and could go for a follow-up every 2 weeks.

\section{Conclusion}

SSNB can be more effective than therapeutic U/S in the management of hemiplegic shoulder pain and could potentially provide a new treatment option for stroke patients.

\section{Acknowledgements \\ Conflicts of interest \\ None declared.}

\section{References}

1 Allen Z, Shanahan EM, Crotty M. Does suprascapular nerve block reduce shoulder pain following stroke: a double-blind randomised controlled trial with masked outcome assessment. BMC Neurol 2010; 10:83-86.

2 Dromerick AW, Edwards DF, Kumar A. Hemiplegic shoulder pain syndrome: frequency and characteristics during inpatient stroke rehabilitation. Arch Phys Med Rehabil 2008; 89:1589-1593.

3 Boonsong P, Jaroenarporrnwatana A, Boonhong A. Preliminary study of suprascapular nerve block (SSNB) in hemiplegic shoulder pain. J Med Assoc Thai 2009; 92:1669-1674. 
4 Teasell R, Foley N, Bhogal SK. Evidence-based review of stroke rehabilitation: painful hemiplegic shoulder. EBRSR 2006; 16:1-35.

5 Lindgen I, Norrving JA, Lindgren A. Shoulder pain after stroke: a prospective population-based study. Stroke 2007; 38:343-348.

6 Suethanapornkul S, Kuptniratsaikul PS, Kuptniratsaikul V, Uthensut P, Dajpratha P, Wongwisethkarn J. Post stroke shoulder subluxation and shoulder pain: a cohort multicenter study. J Med Assoc Thai 2008; 91:1885-1892.

7 Yelnik AP, Colle FM, Bonan IV, Vicaut E. Treatment of shoulder pain in spastic hemiplegia by reducing spasticity of the subscapular muscle: a randomised, double blind, placebo controlled study of botulinum toxin $A$. J Neurol Neurosurg Psychiatry 2007; 78:845-848.

8 Taskaynatan MA, Yilmaz B, Ozgul A, Yazicioglu K, Kalyon TA Suprascapular nerve block versus steroid injection for non-specific shoulder pain. Tohoku J Exp Med 2005; 205:19-25.

9 Shanahan EM, Ahern M, Smith M, Wetherall M, Bresnihan B, FitzGerald O. Suprascapular nerve block (using bupivacaine and methylprednisolone acetate) in chronic shoulder pain. Ann Rheum Dis 2003; 62:400-406.

10 Di Lorenzo L, Pappagallo M, Gimigliano R, Palmieri E, Saviano E, Bello A. Pain relief in early rehabilitation of rotator cuff tendinitis: any role for indirect suprascapular nerve block? Eura Medicophys 2006; 42:195-204.

11 Emery P, Bowman S, Wedderburn L, Grahame R. Suprascapular nerve block for chronic shoulder pain in rheumatoid arthritis. BMJ 1989; 299:1079-1080.

12 Ritchie ED, Tong D, Chung F, Norris AM, Miniaci A, Vairavanathan SD. Suprascapular nerve block for postoperative pain relief in arthroscopic shoulder surgery: a new modality? Anesth Analg 1997; 84:1306-1312.

13 Dromerick AW, Kumar A, Volshteyn O, Edwards DF. Hemiplegic shoulder pain syndrome: interrater reliability of physical diagnosis signs. Arch Phys Med Rehabil 2006; 87:294-295.

14 Neer CS, Welsh RP. The shoulder in sports. Orthop Clin North Am 1997; 8:583-591.

15 Rowe CR. The shoulder. Edinburgh: Churchill Livingstone; 1988.

16 Davies GI, Gould IA, Larson RL. Functional examination of the shoulder girdle. Phys Sports Med 1981; 9:82-104.

17 Train the Brain Forum Committee Thai Mental State Examination (TMSE). Siriraj Hosp Gaz 1993; 45:359-374.

18 Vorster W, Lange CP, Briet RJ, Muller CJ. The sensory branch distribution of the suprascapular nerve: an anatomic study. J Shoulder Elbow Surg 2008; 17:500-502.

19 Fernandes MR, Barbosa MA, Sousa AL, Ramos GC. Suprascapular nerve block: important procedure in clinical practice. Part II. Rev Bras Reumatol 2012; 52:4-9.

20 Checcucci G, Allegra A, Bigazzi P, Gianesello L, Ceruso M, Gritti G. A new technique for regional anesthesia for arthroscopic shoulder surgery based on a suprascapular nerve block and an axillary nerve block: an evaluation of the first results. Arthroscopy 2008; 24:689-696.

21 Matsumoto D, Suenaga N, Oizumi N, Nisada Y, Minami A. A new nerve block procedure for the suprascapular nerve based on a cadaveric study. J Shoulder Elbow Surg 2001; 18: 607-611.
22 Dangoisse MJ, Wilson DJ, Glynn CJ. MRI and clinical study of an easy and safe technique of suprascapular nerve blockade. Acta Anaesthesiol Belg 1994; 45:49-54.

23 Gallagher EJ. Prospective validation of clinically important changes in pain severity measured on a visual analogue scale. Ann Emerg Med 2001; 38:633-638.

24 Croft $P$. Measurement of shoulder related disability: results of a validation study. Ann Rheum Dis 1994; 53:525-528.

25 Nam YS, Jeong JJ, Han SH, Park SE, Lee SM, Know MJ. An anatomic and clinical study of the suprascapular and axillary nerve blocks for shoulder arthroscopy. J Shoulder Elbow Surg 2011; 20:1061-1068.

26 Gado K, Emery P. Modified suprascapular nerve block with bupivacaine alone effectively controls chronic shoulder pain in patients with rheumatoid arthritis. Ann Rheum Dis 1993; 52:215-230.

27 Wassef MR. Suprascapular nerve block. A new approach for the management of frozen shoulder. Anaesthesia 1992; 47:120-124.

28 Dromerick AW, Lang CE, Powers WJ. Very early constraint induced movement therapy (VECTORS): phase ?? trial results [abstract]. Stroke 2007; 38:465-470.

29 Lum PS, Burgar CG, Shor PC. Evidence for improved muscle activation patterns after retraining of reaching movements with the MIME robotic system in subjects with post-stroke hemiparesis. IEEE Trans Neural Syst Rehabil Eng 2004; 12:186-194.

30 Chae J, Fang ZP, Walker M, S Pourmehdi. Intramuscular electromyographically controlled neuromuscular electrical stimulation for upper limb recovery in chronic hemiplegia. Am J Phys Med Rehabil 2001 80:935-994.

31 Itoi E, Kuechle DK, Newman R, Morrey BF, An K. Stabilizing function of the biceps in stable and unstable shoulders. J Bone Joint Surg $\mathrm{Br} 1993$; 75:546-550.

32 Cailliet R. The shoulder in hemiplegia. Philadelphia: A Davis; 1980

33 Lo SF, Chen SY, Lin HS, Jim YF, Meng NH, Kao MJ. Arthrographic and clinical findings in patients with hemiplegic shoulder pain. Arch Phys Med Rehabil 2003; 84:1786-1791.

34 E Yasar, D Vural, I Safaz, B Balaban, B Yilmaz, AS Goktepe, R Alaca Gulhane. Which treatment approach is better for hemiplegic shoulder pain in stroke patients: intra-articular steroid or suprascapular nerve block? A randomized controlled trial Clin Rehabil 2011; 25:60-68.

35 Ben-Aviv D, Boparai N, Wong D, Luu B, Kim E, Mitra R. The efficacy of suprascapular nerve block in treating shoulder pain. Arch Phys Med Rehabil 2007; 88:67-71.

36 Dahan TH, Fortin L, Pelletier M, Petit M, Vadeboncoeur R, Suissa S. Double blind randomized clinical trial examining the efficacy of bupivacaine suprascapular nerve blocks in frozen shoulder. J Rheumatol 2000; 27:1464-1469.

37 Turner-Stokes L, Jackson D. Shoulder pain after stroke: a review of the evidence base to inform the development of an integrated care pathway. Clin Rehabil 2002; 16:276-298. 